\title{
A New Control Strategy for Optimum-Efficiency Operation of a Synchronous Reluctance Motor
}

\author{
Takayoshi Matsuo, Member, IEEE, Ahmed El-Antably, Member, IEEE, and Thomas A. Lipo, Fellow, IEEE
}

\begin{abstract}
In this paper, an optimum-efficiency control scheme of synchronous reluctance motors is presented. There exists a variety of combinations of $d$ - and $q$-axis current which provides a specific motor torque. The objective of the optimum-efficiency controller is to seek a combination of $d$ - and $q$-axis current components, which provides minimum input power, that is, minimum losses at a certain operating point in steady state. A small amount of perturbation is added to the $d$-axis current reference for the purpose of searching a minimum input power operating point.
\end{abstract}

Index Terms-Optimum-efficiency operation, synchronous reluctance motor.

\section{INTRODUCTION}

$\mathbf{E}$ NERGY SAVING is always an important issue for a motor drive system. A number of reports have been published on the subject of efficiency improvement for induction motor drives [4]-[6]. Induction motor efficiency can be improved by means of reduced voltage operation at light loads in the case of fixed frequency induction motor drives. It is also known that induction motor losses at partial loads can be reduced by operating an adjustable-frequency drive at the optimum slip which yields maximum efficiency. In an adjustable-frequency induction motor drive, the voltage and frequency applied to the motor are independently variable, and a specific torque-speed operating point can be achieved with a variety of different voltage frequency combinations. Each voltage frequency pairing defines a particular motor torquespeed characteristic, but motor efficiency may vary widely. If the voltage is high, then magnetizing current and core losses are large. If the voltage is reduced excessively, then motor currents and copper losses may rise. Consequently, there is an optimum voltage and frequency which gives a specified torque and speed with maximum efficiency. At light loads, maximum efficiency will be achieved with a reduced voltage and increased slip, compared with the usual constant voltsper-hertz mode of operation.

This energy-saving measure can also be applied to synchronous reluctance motor drives. In the field-oriented control

Paper IPCSD 97-23, presented at the 1996 Industry Applications Society Annual Meeting, San Diego, CA, October 6-10, and approved for publication in the IEEE TRANSACTIONS ON INDUSTRY APPLICATIONS by the Industrial Drives Committee of the IEEE Industry Applications Society. Manuscript released for publication April 7, 1997

T. Matsuo and T. A. Lipo are with the Department of Electrical and Computer Engineering, University of Wisconsin, Madison, Wisconsin WI 53706 USA (e-mail: matsuot@cae.wisc.edu; lipo@engr.wisc.edu).

A. El-Antably is with Delphi Energy and Engine Management Systems, Indianapolis, IN 46250 USA.

Publisher Item Identifier S 0093-9994(97)06556-0. of synchronous reluctance motors, $d$ - and $q$-axis components of the stator current vector applied to the motor are independently variable, and a specific torque at any motor speed can be achieved with a variety of different $d-q$ current component combinations. Each $d-q$ current component pairing defines a particular motor torque characteristic, but motor efficiency may vary widely. If the $d$-axis current is high, then core losses are large. If the $d$-axis current is reduced excessively, then motor currents and copper losses must increase. Consequently, there is an optimum current vector which gives a specified torque with maximum efficiency at every operating point.

For the practical realization of an efficiency-optimized synchronous reluctance motor drive, an optimum-efficiency controller may be accomplished with the aid of a loss model for the drive into which complete parameter values, including inductance saturation, coefficients of iron losses, temperature, and harmonic effects, must be programmed. At any operating point, the controller performs a computation on optimumefficiency operating conditions and adjusts one, or more, variables in the model until the optimum values are found. These optimized values then become the commanded values for the drive regulator. The effectiveness of this approach obviously depends on the accuracy of the loss model.

Optimization can be accomplished by measuring the power input to the drive and perturbing one variable while seeking the minimum input power at the particular operating point. The minimization of total power input may not be a very sensitive procedure for minimization of losses, but accurate loss modeling and precise information regarding parameter values are not required. A block diagram for implementing the proposed optimum-efficiency controller of the synchronous reluctance motor is presented, and the overall control strategy for searching the minimum input power is discussed. An optimum-efficiency controller of the synchronous reluctance motor drive was implemented in the laboratory to verify the developed control scheme, and an experimental study was carried out with the implemented drive system.

\section{II. $D-Q$ EQUATIONS OF A SYNCHRONOUS RELUCTANCE MOTOR}

Since the stator winding of the synchronous reluctance machine is sinusoidally distributed, flux harmonics in the airgap contribute only an additional term to the stator leakage inductance. Hence, the equations which describe the behavior of the synchronous reluctance machine can be derived from the conventional equations depicting a conventional wound-field synchronous machine. In synchronous reluctance machines, 
the excitation (field) winding is nonexistent. Also, in machines typically employing a modern axially laminated rotor structure, a rotor cage is normally omitted since the machine can be starting synchronously from rest by proper inverter control. Hence, eliminating both the field-winding and damper-winding equations from Park's equations forms the basis for the $d-q$ equations for a synchronous reluctance machine [3]. That is, in synchronous reference frame,

$$
\begin{aligned}
& v_{d s}=r_{s} i_{d s}+p \lambda_{d s}-\omega_{r} \lambda_{q s} \\
& v_{q s}=r_{s} i_{q s}+p \lambda_{q s}+\omega_{r} \lambda_{d s} \\
& \lambda_{d s}=L_{l s} i_{d s}+L_{m d} i_{d s} \\
& \lambda_{q s}=L_{l s} i_{q s}+L_{m q} i_{q s}
\end{aligned}
$$

and where $L_{l s}, L_{m d}$, and $L_{m q}$ are, respectively, the stator leakage inductance, direct axis magnetizing inductance, and quadrature axis magnetizing inductance. The quantity $r_{s}$ is the stator resistance per phase.

In terms of the $d-q$ variables, the electromagnetic torque is identical to that of a synchronous machine, namely,

$$
T_{e}=\frac{3}{2} \frac{P}{2}\left(\lambda_{d s} i_{q s}-\lambda_{q s} i_{d s}\right)
$$

where $P$ is the number of poles. The electromagnetic torque $T_{e}$ can be described also as

$$
T_{e}=\frac{3}{2} \frac{P}{2}\left(L_{d s}-L_{q s}\right) i_{d s} i_{q s}
$$

\section{Constant-Torque Operation FOR VARIOUS CURRENT VECTORS}

To produce certain constant torque $T_{e}^{*}$, the required $q$-axis current $I_{q s}$ can be expressed in terms of $d$-axis current $I_{d s}$ as

$$
I_{q s}=\frac{T_{e}^{*}}{\frac{3}{2} \frac{P}{2}\left(L_{d s}-L_{q s}\right) I_{d s}} .
$$

Using (7) for the expression of $I_{q s}$, the stator phase current $I_{s}$ and phase voltage are also expressed as a function of the $d$-axis current $I_{d s}$ :

$$
I_{s}=\sqrt{I_{d s}^{2}+\left(\frac{T_{e}^{*}}{\frac{3}{2} \frac{P}{2}\left(L_{d s}-L_{q s}\right) I_{d s}}\right)^{2}} .
$$

Figs. 1 and 2 show variation of stator current $I_{s}$ and $q$-axis current $I_{q s}$, and stator voltage $V_{s}$ as a function of $d$-axis current $I_{d s}$ for constant torque operation of 0.25 per unit. The parameters of the experimental motor are used for the calculation, which are as follows: the number of poles $P=4$, $d$ - and $q$-axis inductances $L_{d s}=0.103, L_{q s}=0.016$ in henrys, the stator resistance $r_{s}=1.58 \Omega$, the motor torque $T_{e}^{*}=2.2 \times 0.25(\mathrm{~N} \cdot \mathrm{m})$. The calculations include the effects of the saturation of inductance $L_{d s}$, which is a function of the $d$-axis current $I_{d s}$. Larger value of $I_{q s}$ is required to produce a specific torque when $L_{d s}$ decreases due to saturation. Fig. 1 shows that there exists an operating point which gives a minimum current condition, where $I_{d s}$ is $1.4 \mathrm{~A}$ and $I_{q s}$ is 1.6 A. Without the saturation effect, the minimum current

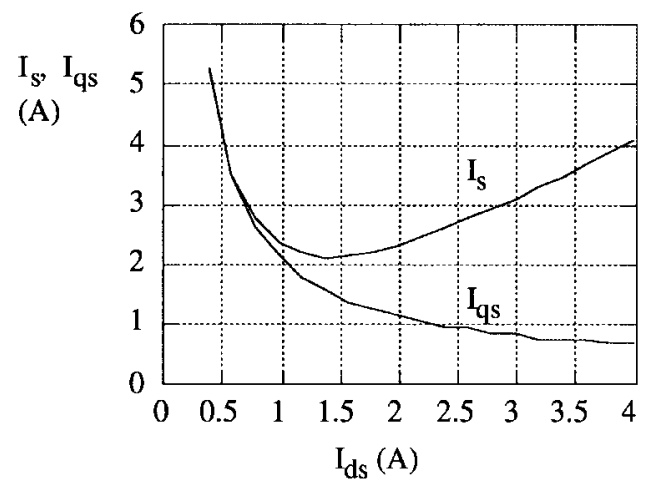

Fig. 1. Variation of the $q$-axis current $I_{q s}$ and the phase current $I_{s}$ as a function of $d$-axis current $I_{d s}$ for constant-torque operation of 0.25 per unit, where the effect of saturation of $d$-axis inductance $L_{d s}$ is included.

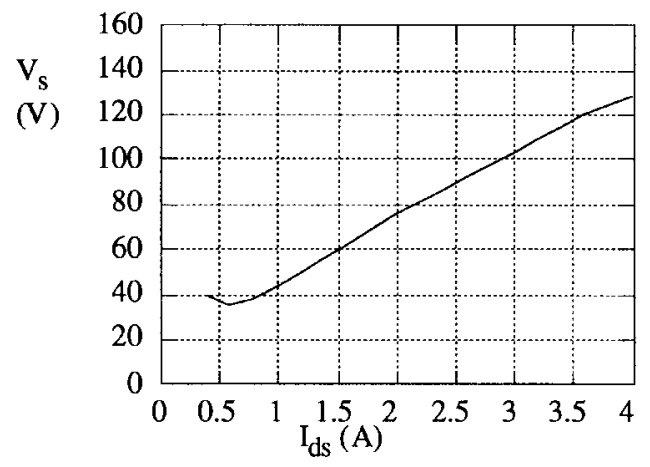

Fig. 2. Variation of stator voltage $V_{s}$ as a function of $d$-axis current $I_{d s}$ for constant torque operation of 0.25 per unit, where the effect of saturation of $d$-axis inductance $L_{d s}$ is included.

condition occurs at the operating point where $I_{d s}=I_{q s}$. A lookup table for $L_{d s}$ as a function of $I_{d s}$ was used to obtain Fig. 1, where the table was obtained from the measurement results of the experimental synchronous reluctance motor [7].

\section{IRON AND COPPER LOSSES}

When evaluating the core loss, the different behavior of hysteresis and eddy-current losses with respect to frequency is taken into account. At fundamental frequency $f$, the core losses are described as

$$
W_{\text {core }}=k_{h} f \phi^{2}+k_{e} f^{2} \phi^{2}
$$

where $\phi$ is the magnetic flux and $k_{h}$ and $k_{e}$ are the hysteresis and eddy-current coefficients, respectively. Since the motor voltage (airgap voltage) is expressed as $V_{m}=k_{c} f \phi$, the fundamental core loss is written as

$$
W_{\text {core }}=V_{m}^{2} \frac{\left(\frac{k_{h}}{f}+k_{e}\right)}{k_{c}^{2}}=k V_{m}^{2}
$$

where

$$
k=\frac{\left(\frac{k_{h}}{f}+k_{e}\right)}{k_{c}^{2}} .
$$




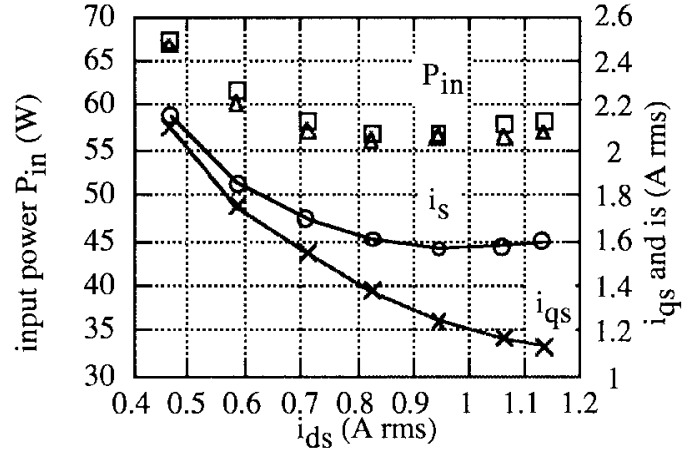

(a)

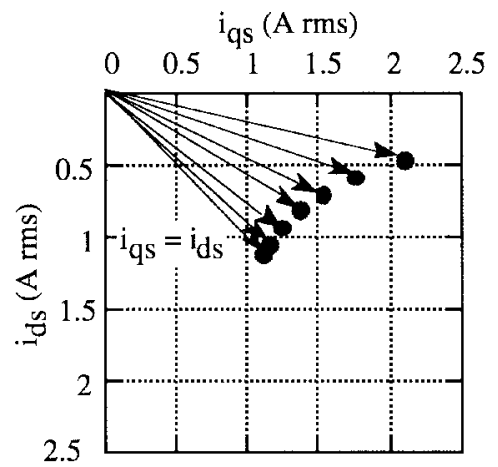

(b)

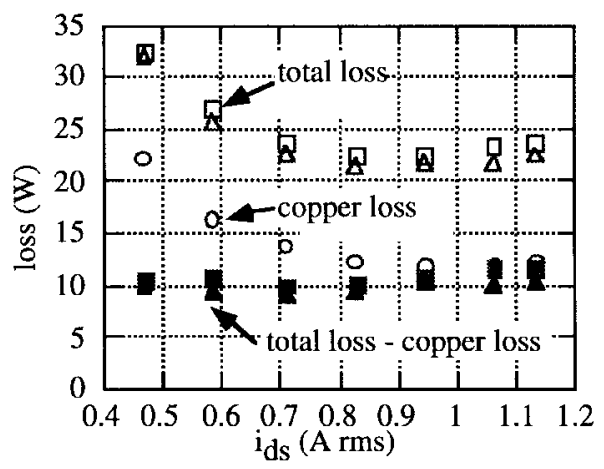

(c)

Fig. 3. Experimental results of (a) input power $P_{i n}$, stator current $i_{s}$, and $q$-axis current $i_{q s}$ versus $d$-axis current $i_{d s}$, (b) various stator current vectors, (c) total losses, copper loss, and iron losses (plus stray load losses) versus $d$-axis current $i_{d s}$, where the rotor speed is controlled at $600 \mathrm{r} / \mathrm{min}$ and the dc dynamometer provides the load torque of $0.55 \mathrm{~N} \cdot \mathrm{m}$.

The copper loss is expressed in terms of stator resistance $r_{s}$ and stator current $I_{s}$ as

$$
W_{\text {copper }}=3 r_{s} I_{s}^{2} \text {. }
$$

The loss $W_{t}$, which includes the fundamental core loss and the copper loss, is

$$
\begin{aligned}
W_{t} & =W_{\text {core }}+W_{\text {copper }} \\
& =k V_{m}^{2}+3 r_{s} I_{s}^{2} .
\end{aligned}
$$

Using the following expressions for $V_{m}^{2}$ and $I_{s}^{2}$,

$$
\begin{aligned}
V_{m}^{2} & =\left(\omega_{r} L_{m d} I_{d s}\right)^{2}+\left(\omega_{r} L_{m q} I_{q s}\right)^{2} \\
I_{s}^{2} & =i_{q s}^{2}+I_{d s}^{2}
\end{aligned}
$$

the loss $W_{t}$ can be expressed in terms of $d$-axis current as

$$
\begin{aligned}
W_{t}= & k\left(\left(\omega_{r} L_{m d} I_{d s}\right)^{2}\right. \\
& \left.+\left(\omega_{r} L_{m q} \frac{T_{e}^{*}}{\frac{3}{2} \frac{P}{2}\left(L_{d s}-L_{q s}\right) I_{d s}}\right)^{2}\right) \\
& +3 r_{s}\left(\left(\frac{T_{e}^{*}}{\frac{3}{2} \frac{P}{2}\left(L_{d s}-L_{q s}\right) I_{d s}}\right)^{2}+I_{d s}^{2}\right) .
\end{aligned}
$$

Equation (16) can be written as

$$
W_{t}=a I_{d s}^{2}+b I_{d s}^{-2}
$$

and derivative of $W_{t}$ in terms of $I_{d s}$ is described as

$$
\begin{aligned}
\frac{d W_{t}}{d I_{d s}}= & 2 a I_{d s}^{-3}\left(I_{d s}^{2}+\sqrt{\frac{b}{a}}\right)\left(I_{d s}+\left(\frac{b}{a}\right)^{1 / 4}\right) \\
& \cdot\left(I_{d s}-\left(\frac{b}{a}\right)^{1 / 4}\right)
\end{aligned}
$$

where

$$
\begin{aligned}
& a=\frac{\left(\frac{k_{h}}{f}+k_{e}\right)}{k_{c}^{2}}\left(\omega_{r} L_{m d}\right)^{2}+3 r_{s} \\
& b=\left(\frac{\left(\frac{k_{h}}{f}+k_{e}\right)}{k_{c}^{2}}\left(\omega_{r} L_{m q}\right)^{2}+3 r_{s}\right)\left(\frac{T_{e}^{*}}{\frac{3}{2} \frac{P}{2}\left(L_{d s}-L_{q s}\right)}\right)^{2} .
\end{aligned}
$$

Equation (18) indicates that $d W_{t} / d I_{d s}<0$ when $I_{d s}<\left(\frac{b}{a}\right)^{1 / 4}$ and $d W_{t} / d I_{d s}>0$ when $I_{d s}>\left(\frac{b}{a}\right)^{1 / 4}$, which means that there exists a minimum $W_{t}$ at a specific value of $I_{d s}$. The minimum loss $W_{t-m i n}$ is given by

$$
W_{t-m i n}=a I_{d s-m i n}^{2}+b I_{d s-m i n}^{-2}+c
$$

in which

$$
I_{d s-\min }=\left(\frac{b}{a}\right)^{1 / 4} .
$$




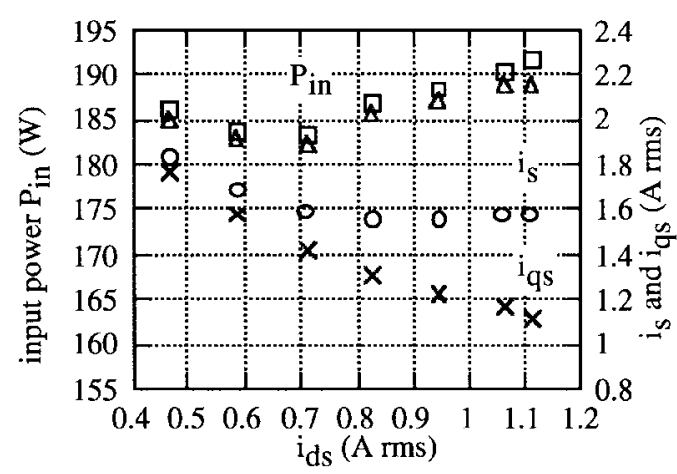

(a)

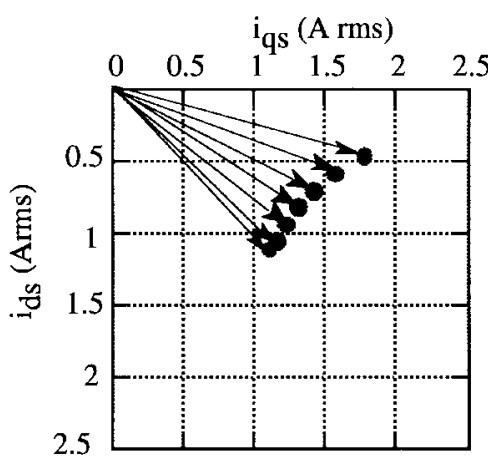

(b)

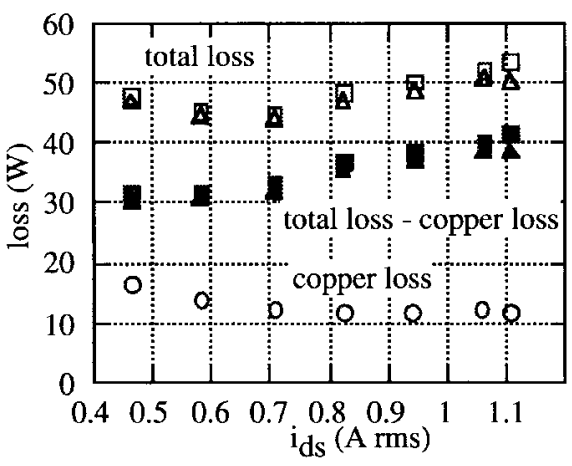

(c)

Fig. 4. Experimental results of (a) input power $P_{i n}$, stator current $i_{s}$, and $q$-axis current $i_{q s}$ versus $d$-axis current $i_{d s}$, (b) various stator current vectors, (c) total losses, copper loss, and iron losses (plus stray load losses) versus $d$-axis current $i_{d s}$, where the rotor speed is controlled at 2400 r/min and the dc dynamometer provides the load torque of $0.55 \mathrm{~N} \cdot \mathrm{m}$.

\section{EXPERIMENTAL STUDY OF INPUT POWER OF SYNCHRONOUS RELUCTANCE MOTOR DRIVE}

An experimental study of the input power of the synchronous reluctance motor drive was carried out with the implemented experimental drive system. The speed of the synchronous reluctance motor is controlled at a certain speed and a partial load is applied to the motor by a dynamometer. The tested speeds were $600,1200,1800$, and $2400 \mathrm{r} / \mathrm{min}$, and the applied load is $0.55 \mathrm{~N} \cdot \mathrm{m}$, that is, $25 \%$ of the rated torque of the experimental motor. The input power was measured at the dc bus of the inverter for various combinations of $d$ - and $q$-axis current components in the steady-state condition.

Fig. 3(a) shows plots of input power $P_{i n}$, stator current $i_{s}$, and $q$-axis current $i_{q s}$ for various $d$-axis current $i_{d s}$, where the rotor speed is controlled by the synchronous reluctance motor at $600 \mathrm{r} / \mathrm{min}$, and the dc dynamometer provides the load torque of $0.55 \mathrm{~N} \cdot \mathrm{m}$. The $q$-axis current $i_{q s}$ increases as $d-$ axis current $i_{d s}$ decreases to maintain output torque constant. Fig. 3(a) indicates that there exists a minimum input power operating point at about $i_{d s}=0.9 \mathrm{~A}$, while the stator current $i_{s}$ has minimum value at about $i_{d s}=0.95 \mathrm{~A}$. It should be noted that there exists only one $i_{d s}-i_{q s}$ combination which provides minimum input power for this specific operating condition.

Fig. 3(b) illustrates the current vectors which produce the same torque of $0.55 \mathrm{~N} \cdot \mathrm{m}$ at $600 \mathrm{r} / \mathrm{min}$. Fig. 3(c) shows experimental results of losses. The total loss is obtained by subtracting the output power from the measured input power. The plotted total loss includes motor losses and inverter losses, where the input power is obtained from the measured dc-bus current and dc-bus voltage. The copper loss is calculated from the measured motor phase current using the measured stator resistance $r_{s}$. The difference between the total loss and the copper loss is also plotted in the figure, which includes iron losses, inverter losses and stray load losses.

Fig. 4 shows the plots of the same items as Fig. 3 in the case of the rotor speed of $2400 \mathrm{r} / \mathrm{min}$, where the load torque of $0.55 \mathrm{~N} \cdot \mathrm{m}$ is the same as in the previous case. Fig. 4(a) shows the plots of input power $P_{i n}$, stator current $i_{s}$, and $q$ axis current $i_{q s}$ for various $d$-axis current $i_{d s}$. Again, the result indicates that there exists a minimum input power operating point between $i_{d s}=0.6$ and $0.7 \mathrm{~A}$, while the stator current $i_{s}$ has minimum value at about $i_{d s}=0.9 \mathrm{~A}$. Fig. $4(\mathrm{~b})$ illustrates the current vectors which produce the same torque of 0.55 $\mathrm{N} \cdot \mathrm{m}$ at $2400 \mathrm{r} / \mathrm{min}$. Fig. 4(c) shows experimental results of losses, where the total loss, the copper loss, and the difference between the total loss and the copper loss are plotted.

It should be noted that the minimum input power operating point for the rotor speed of $2400 \mathrm{r} / \mathrm{min}$ is shifted to the lower $i_{d s}$ value compared to the one for the rotor speed of $600 \mathrm{r} / \mathrm{min}$. The difference of the total loss from the copper loss, of which the main part of the losses are the core losses, increases three times as the rotor speed increases from 600 to $2400 \mathrm{r} / \mathrm{min}$, while the copper loss remains in almost the same range as the rotor speed increases.

Fig. 5 provides the additional experimental results of the measured input power for different rotor speeds. It can be found that each operating condition has a unique combination 


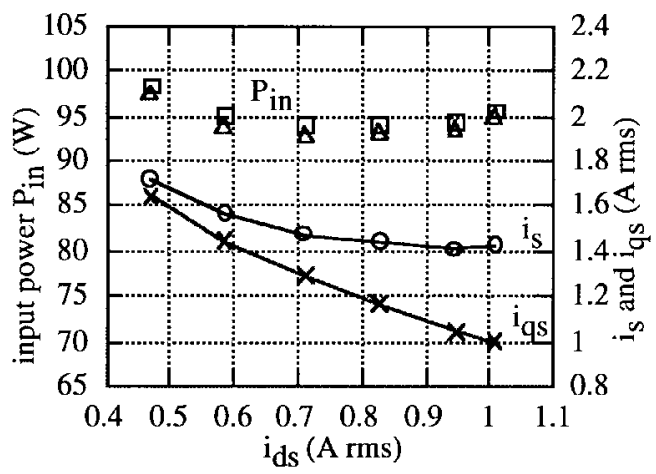

(a)

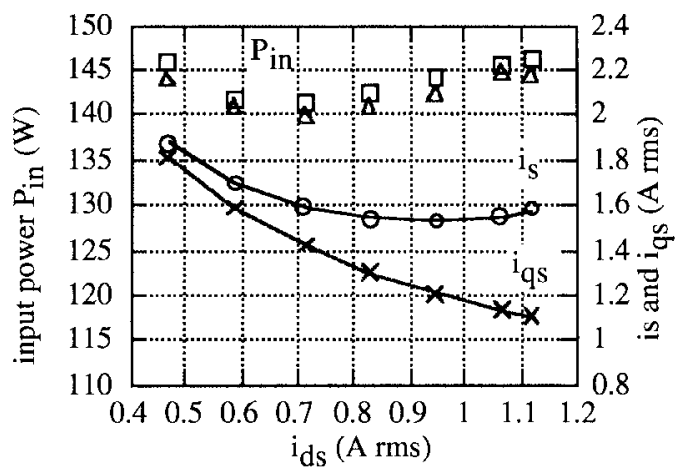

(b)

Fig. 5. Experimental results of input power $P_{i n}$, stator current $i_{s}$, and $q$-axis current $i_{q s}$ versus $d$-axis current $i_{d s}$, where the rotor speed is controlled at (a) $1200 \mathrm{r} / \mathrm{min}$ and (b) $1800 \mathrm{r} / \mathrm{min}$ and dc dynamometer provides the load torque of $0.55 \mathrm{~N} \cdot \mathrm{m}$.

of $d$ - and $q$-axis currents that provides minimum input power at the inverter dc bus.

Fig. 6 shows plots of the loss term, which is the difference between the total loss and the copper loss, that is, mainly iron losses versus $d$-axis current $i_{d s}$ for different operating speed, while a de dynamometer provides the load torque of $0.55 \mathrm{~N} \cdot \mathrm{m}$. Fig. 7 shows the plots of the loss versus stator frequency for different $d$-axis current, while a dc dynamometer provides the load torque of $0.55 \mathrm{~N} \cdot \mathrm{m}$.

\section{OPTIMUM-EFFICIENCY CONTROLLER}

Fig. 8 shows a control configuration of the optimumefficiency controller of a synchronous reluctance motor drive with a torque and speed control function.

By means of an absolute encoder or resolver, the sine and cosine of the angular position of the rotor is established. These sinusoidal components are used to refer those physical stator currents from the physical (stationary) reference frame to the rotating $(d-q)$ axes. The encoder is also used to measure speed and, based on the speed measurement, the desired (command) values of $i_{d s}$ and $i_{q s}$ are established. Current regulators guarantee that the desired and actual values of the $d-q$ currents are obtained. The voltage command signals which are obtained in the synchronously rotating $d-q$ frame are finally referred back to the stator frame before being used to switch the voltage source pulsewidth modulation (PWM) inverter [6].

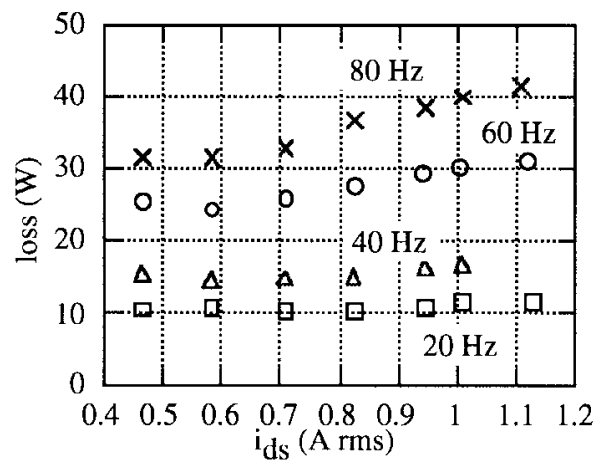

Fig. 6. Experimental results of losses including iron losses and stray load losses versus $d$-axis current $i_{d s}$, where the load torque is $0.55 \mathrm{~N} \cdot \mathrm{m}$.

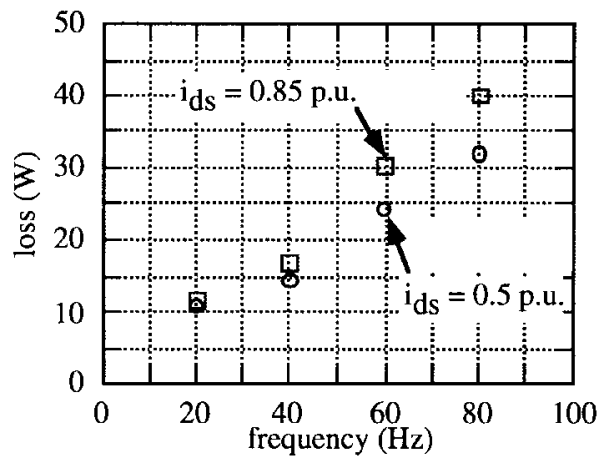

Fig. 7. Experimental results of losses including iron losses and stray load losses versus stator frequency for two different $d$-axis current conditions, where the load torque is $0.55 \mathrm{~N} \cdot \mathrm{m}$.

The motor torque of synchronous reluctance motors is proportional to two components of the stator current vector, that is, $d$ - and $q$-axis current, $i_{d s}$ and $i_{q s}$. Hence, there exist various combinations of $d$ - and $q$-axis current which provide a certain amount of motor torque. The objective of the optimumefficiency controller is to seek a combination of $d$ - and $q$-axis current components, which provides minimum input power, that is, minimum losses at a certain operating point in steady state. A small amount of perturbation is added to the $d$-axis current reference $i_{d s}^{*}$ for the purpose of searching a minimum input power operating point. The input power of the inverter is calculated from the measured dc-bus current and dc-bus voltage of the inverter. The dc-bus current was measured with a dc-current sensor and a 12-b A/D converter. The obtained input power includes motor output power, motor losses, and inverter losses. The motor losses include copper losses, iron losses, and stray load losses.

Fig. 9 illustrates stator current vectors to which small perturbations are superimposed to find an optimum-efficiency operating point. First, $d$-axis current reference $i_{d s}^{*}$ is changed by small amount $\Delta i_{d s}^{*}$. If $d$-axis current is decreased, then the motor torque decreases and, consequently, the motor speed is decreased, where it is assumed that the load torque is constant. The error between speed reference and speed feedback increases and, then, the output of the speed controller, that is, the torque command $i_{q s}^{*}$ increases. The motor torque increases as $q$-axis current $i_{q s}$ increases up to the same amount of the load torque. The torque at two operating points is 


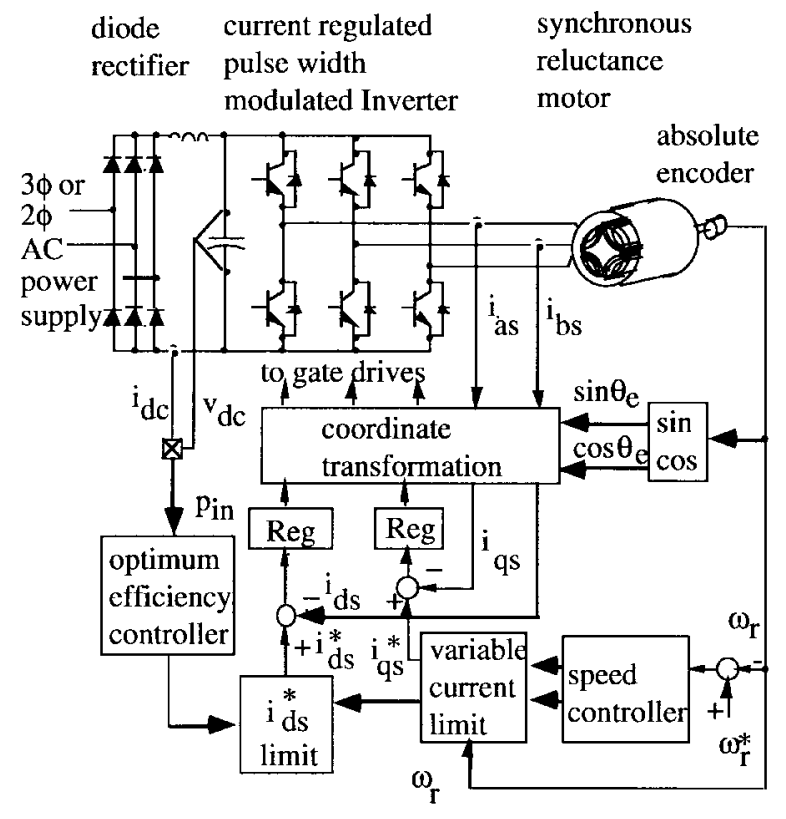

Fig. 8. An optimum-efficiency control configuration for a synchronous reluctance motor drive.

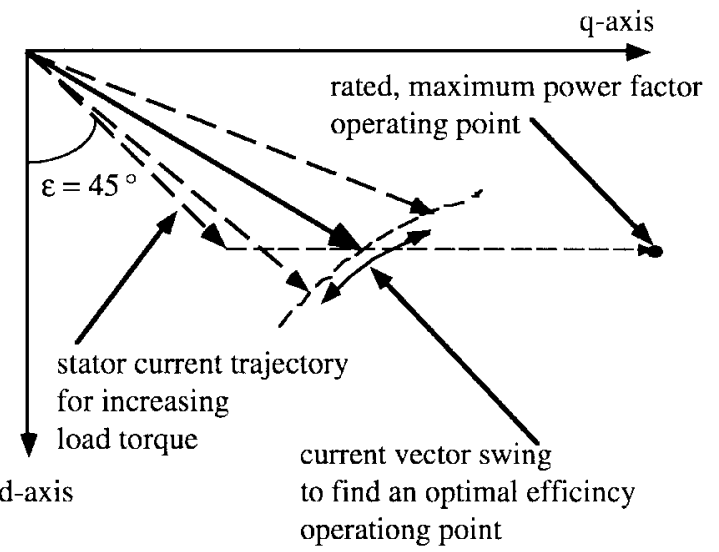

Fig. 9. Illustration of current vector swing to find an optimum-efficiency operating point where current vectors provide the same motor torque.

expressed as

$$
\begin{aligned}
T_{e 1} & =\frac{3}{2} \frac{P}{2}\left(L_{d s 1}-L_{q s 1}\right) i_{d s 1} i_{q s 1} \\
& =\frac{3}{2} \frac{P}{2}\left(L_{d s 2}-L_{q s 2}\right)\left(i_{d s 1}-\Delta i_{d s}\right)\left(i_{q s 1}+\Delta i_{q s}\right)
\end{aligned}
$$

where the quantities with subscripts 1 or 2 denote quantities at each operating point. At the operating point $2, i_{d s 2}=$ $i_{d s 1}-\Delta i_{d s}$ and $i_{q s 2}=i_{q s 1}-\Delta i_{q s}$.

Fig. 10 illustrates a pattern of $d$-axis current perturbation to find an optimum-efficiency operating point. It is assumed that the motor is generating a partial load torque at a certain speed, where $d$-axis current reference is $i_{d s 1}^{*}=i_{d s}^{*}(5)$ at an operating point. In this pattern, first, $d$-axis current reference $i_{d s}^{*}$ is decreased five steps, $\Delta i_{d s}^{*}$ each step. Then, $d$-axis current reference $i_{d s}^{*}$ is increased ten steps, again, $\Delta i_{d s}^{*}$ each step. The input power is measured at each step while $d$-axis current reference $i_{d s}^{*}$ is increased from $i_{d s}^{*}(0)$ to $i_{d s}^{*}(10)$ and, then, the optimum-efficiency controller determines at which step the

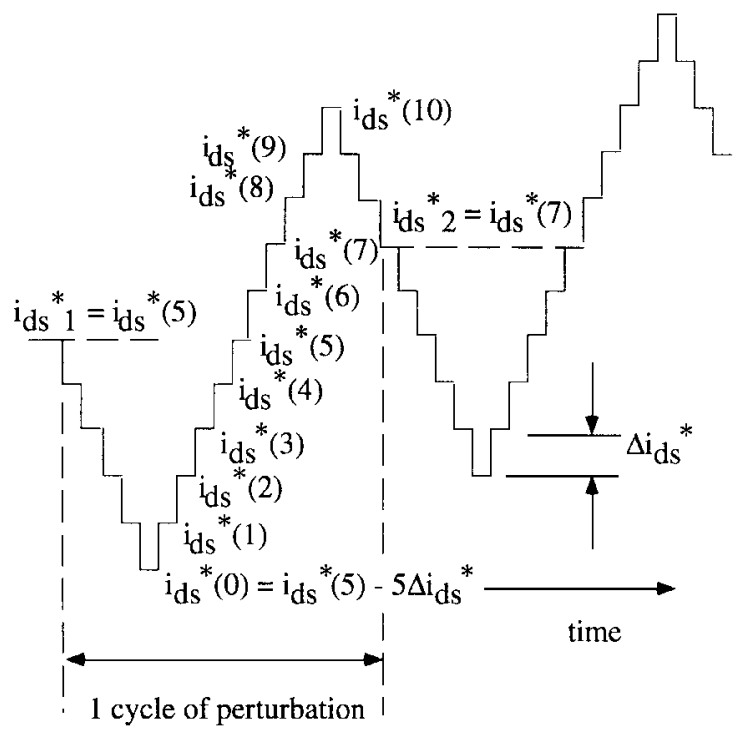

Fig. 10. Illustration of a pattern of $d$-axis current perturbation to find an optimum-efficiency operating point.

(a)

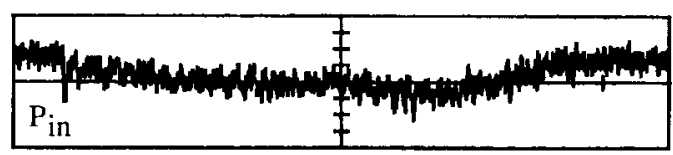

(b)

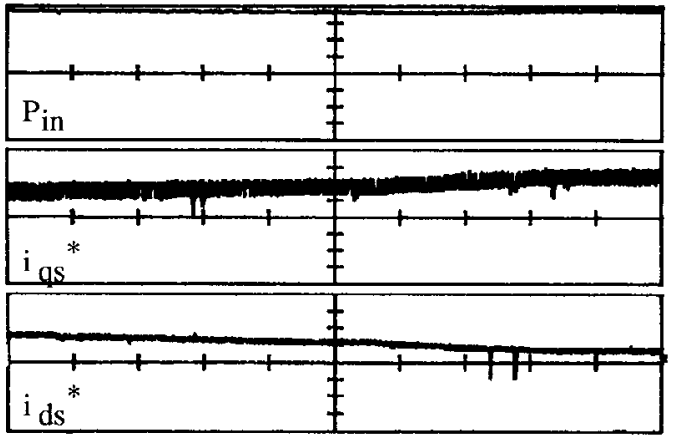

Fig. 11. Experimental result of a behavior of input power $P_{i n}$ for continuous change of $d$-axis current $i_{d s}$, while the rotor speed is controlled at $1800 \mathrm{r} / \mathrm{min}$ and $\mathrm{dc}$ dynamometer provides the load torque of $0.55 \mathrm{~N} \cdot \mathrm{m}$. (a) Measured input power (1.865 W/div). (b) Measured input power (37.3 W/div). (c) $q$-axis current (1.0 A/div). (d) $d$-axis current $(1.0 \mathrm{~A} /$ div). The time scale is $5 \mathrm{~s} /$ div.

input power has a minimum value. The controller decreases $d$-axis current reference to the current level where the input power has its minimum value. In this example, the input power has its minimum value at $i_{d s}^{*}(7)$ and $i_{d s 2}^{*}=i_{d s}^{*}(7)$ is the $d$-axis current reference at the next operating point. The amount of $d$-axis step change should be small enough not to create any significant torque disturbance to the drive system. The time period of one step change must be determined by the response time of the drive system against small $i_{d s}$ disturbance.

\section{AN EXPERIMENTAL STUDY OF THE IMPLEMENTED OPTIMUM-EFFICIENCY CONTROLLER}

The optimum-efficiency controller was implemented with digital signal processor (DSP) software, and an experimental study of the optimum-efficiency control of the synchronous reluctance motor drive was carried out with the implemented drive system. 
(a)

(b)

(c)

(d)

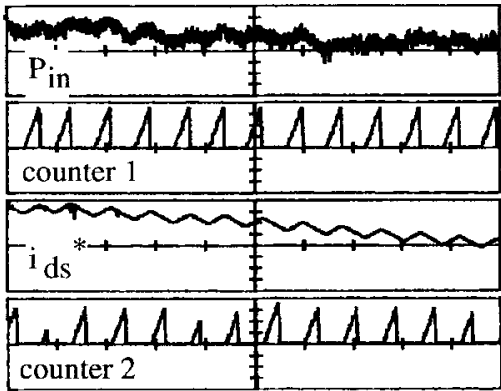

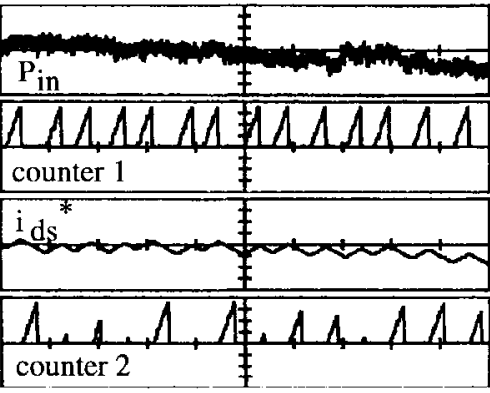

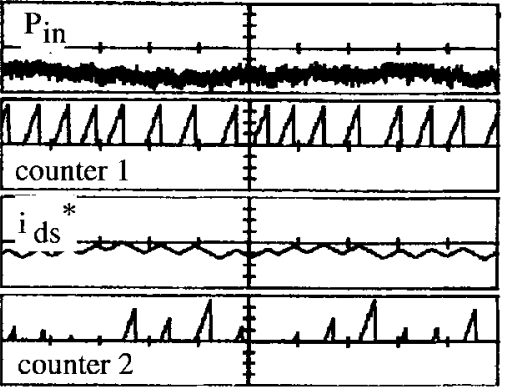

Fig. 13. Experimental results of the optimum-efficiency control of a synchronous reluctance motor. The rotor speed is controlled at 1800 r/min and dynamometer provides the load torque of $0.55 \mathrm{~N} \cdot \mathrm{m}$. (a) Measured input power $(1.865 \mathrm{~W} / \mathrm{div})$. (b) Counter 1 . (c) $d$-axis current reference (0.125 A/div). (d) Counter 2. Time scale is $50 \mathrm{~s} /$ div.

The important issues to be addressed in the laboratory experimental study included the following:

1) behavior of the input power while $d$-axis current is continuously decreased from the rated operating condition;

2) response of the input power to a small $d$-axis current step;

3) optimum-efficiency control performance study.

Fig. 11 shows an experimental result of a behavior of input power $P_{i n}$ for continuous change of $d$-axis current $i_{d s}$, while the rotor speed is controlled at $1800 \mathrm{r} / \mathrm{min}$ and dc dynamometer provides the load torque of $0.55 \mathrm{~N} \cdot \mathrm{m}$. The trace of input power $P_{i n}$ indicates that there exists an operating point where the input power has a minimum value, where the $d$-axis current was decreased with a constant reduction rate of the $d$-axis current simply to determine if there was an operating point with a minimum input power. The exact steady-state condition at each operating point was not established with this sweeping operation. In this case, the efficiency improvement of about 4 $\mathrm{W}$ is expected while the motor output power is $104 \mathrm{~W}$. At this speed the motor full power is $415 \mathrm{~W}$.

Fig. 12 shows an experimental result of a response of input power $P_{i n}$ for a step change of $d$-axis current $i_{d s}^{*}$, while the rotor speed is controlled at $1800 \mathrm{r} / \mathrm{min}$ and dc dynamometer provides the load torque of $0.55 \mathrm{~N} \cdot \mathrm{m}$.

The input power decreased by about $0.5 \mathrm{~W}$ when the $d$-axis current was increased by $40 \mathrm{~mA}$, which is about $2 \%$ of the rated $d$-axis current, as shown in Fig. 12(a). In the other case, the input power increased by about $0.7 \mathrm{~W}$ when the $d$-axis current was decreased by $40 \mathrm{~mA}$, as shown in Fig. 12(b). The input power is not always strictly constant, as expected, and even in the experimental system, an input power fluctuation of about $1 \mathrm{~W}$ was observed when the output power is $104 \mathrm{~W}$.

Fig. 13 shows a process of the optimum-efficiency control, where the input power is gradually minimized. Counter 1 counts up from zero to ten as the $d$-axis current reference is increased stepwise at every perturbation cycle, which is described in Fig. 10. The number of steps is ten in this case. Counter 2 counts down to the $d$-axis current reference where the input power is minimized among the perturbation at a specific perturbation cycle. The rotor speed is controlled at $1800 \mathrm{r} / \mathrm{min}$ and the dc dynamometer provides the load torque of $0.55 \mathrm{~N} \cdot \mathrm{m}$, while the optimum-efficiency controller seeks an operating point which provides the minimization of the input power. In this case, the improvement of the input power is
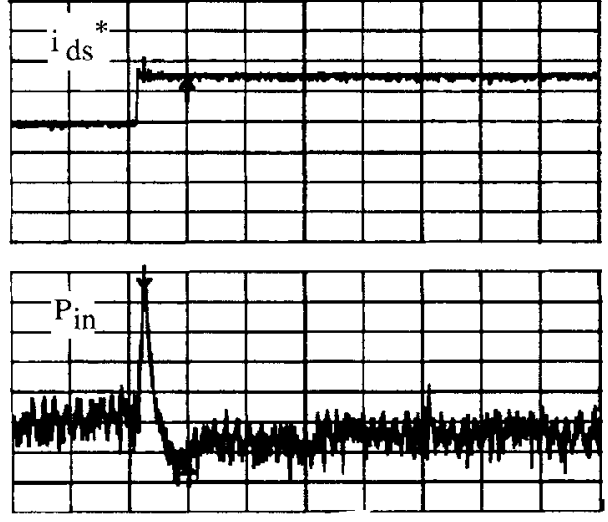

(a)
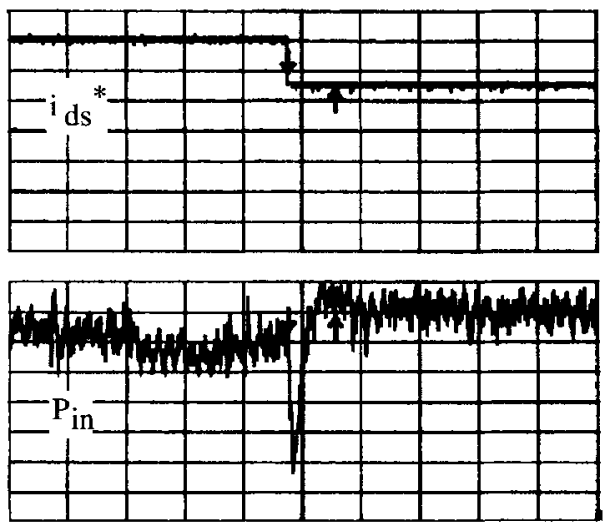

(b)

Fig. 12. Experimental result of a response of input power $P_{i n}$ for a step change of $d$-axis current $i_{d s}^{*}$, while the rotor speed is controlled at $1800 \mathrm{r} / \mathrm{min}$ and dc dynamometer provides the load torque of $0.55 \mathrm{~N} \cdot \mathrm{m}$. (a) and (b): (top) $d$-axis current reference $(0.4 \mathrm{~A} / \mathrm{div})$; (bottom) measured input power $(0.746$ $\mathrm{W} / \mathrm{div})$. Time scale is $2 \mathrm{~s} / \mathrm{div}$.

about 6-7 W. The motor output power is $104 \mathrm{~W}$ at this speed, while the motor full power is $415 \mathrm{~W}$.

\section{CONCLUSION}

The purpose of this paper was to present an optimumefficiency control strategy for a synchronous reluctance motor drive, where the on-line controller seeks a combination of $d$ and $q$-axis current components, which provides minimum input power, that is, minimum losses at a certain operating point in steady state. A small amount of perturbation is added to the 
$d$-axis current reference $i_{d s}^{*}$ for the purpose of searching a minimum input power operating point. The input power of the inverter is calculated from the measured dc-bus current and dcbus voltage of the inverter. The obtained input power includes motor output power, motor losses, and inverter losses. A block diagram for implementing the proposed optimum-efficiency controller of the synchronous reluctance motor was presented, and the overall control strategy for searching the minimum input power was discussed. An optimum-efficiency controller of the synchronous reluctance motor drive was implemented in the laboratory to verify the developed control scheme.

\section{REFERENCES}

[1] T. A. Lipo, "Synchronous reluctance machines-A viable alternative for AC drives?," Elec. Mach. Power Syst., vol. 19, pp. 659-671, Nov./Dec. 1991.

[2] T. Matsuo and T. A. Lipo, "Field oriented control of synchronous reluctance machine," in Conf. Rec. IEEE Power Electronics Specialists Conf., June 1993, pp. 425-431.

[3] D. W. Novotny and T. A. Lipo, Vector Control and Dynamics of AC Drives. London, U.K.: Oxford Univ. Press, 1996.

[4] A. Kusko and D. Galler, "Control means for minimization of losses in AC and DC motor drives," IEEE Trans. Ind. Applicat., vol. IA-19, pp. 561-570, July/Aug. 1983.

[5] D. S. Kirschen, D. W. Novotny, and T. A. Lipo, "On-line efficiency optimization of a variable frequency induction motor drive," IEEE Trans. Ind. Applicat., vol. IA-21, pp. 610-616, May/June 1985.

[6] J. M. D. Murphy and V. B. Honsinger, "Efficiency optimization of inverter-fed induction motor drives," in Conf. Rec. IEEE Annu. Meeting, 1982, pp. 544-552.

[7] T. Matsuo and T. A. Lipo, "Rotor design optimization of synchronous reluctance machine," IEEE Trans. Energy Conversion, vol. 9, pp. 359-365, June 1994.

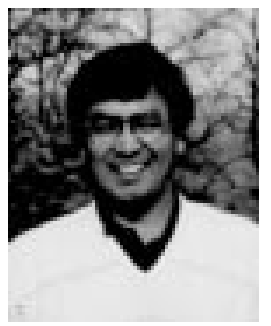

Takayoshi Matsuo (S'90-M'92) was born in Himeji, Japan. He received the B.E. degree in electrical engineering and the M.E. degree in applied electronics from Tokyo Institute of Technology, Tokyo, Japan, in 1975 and 1977, respectively, and the M.S. and Ph.D. degrees in electrical engineering from the University of Wisconsin, Madison, in 1983 and 1994, respectively.

From 1977 to 1989, he was an Electrical Engineer in the Power Electronics Department, Mitsubishi Electric Corporation. Since 1994, he has been a Research Associate at the Wisconsin Power Electronics Research Center, Department of Electrical and Computer Engineering, University of Wisconsin, where he has worked on various research and development projects. His research interests include ac drives, power electronics, and electrical machines.

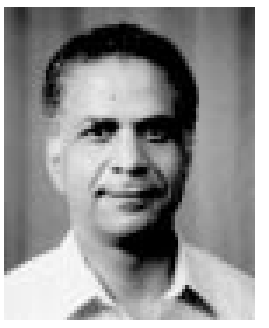

Ahmed El-Antably (M'85) received the B.S. degree in electrical engineering from Cairo University, Cairo, Egypt, in 1968 and the M.S. degree in control engineering and the Ph.D. degree in electrical engineering from the University of Sussex, U.K., in 1975 and 1980, respectively.

He worked in various oil fields pumping stations from 1968 to 1973 . He was with Westinghouse Electric Corporation from 1980 to 1989 , involved in the design, analysis, manufacturing, testing, and service of electric drive motor systems of directcurrent, induction, synchronous, and permanent-magnet motors of many sizes for industrial, commercial, and military applications. He also spent some time at the Westinghouse Research and Development Center, designing energyefficient synchronous reluctance machines. He was also engaged in control systems analysis for Westinghouse nuclear power plants. In 1989, he joined AC Delco Systems-General Electric Corporation (now Delphi Energy and Engine Management Systems), where he is currently a Staff Engineer involved in the development, design, and support of electric drive motors for various electric propulsion systems, including the drive motor for the GM electric vehicle (EV1) program, electric hybrid shuttle buses, electric hybrid vans, and large electric drive motors for military applications. He is also responsible for developing advanced second-generation drive motors for future electric propulsion applications. He is the author of 15 publications and the holder of four patents.

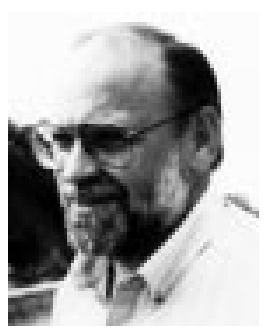

Thomas A. Lipo (M'64-SM'71-F'87) is a native of Milwaukee WI.

He is currently the Grainger Professor for Power Electronics and Electrical Machines, Department of Electrical and Computer Engineering, University of Wisconsin, Madison. His interests span power electronics, electric machines, and motor drives.

Dr. Lipo received the Outstanding Achievement Award from the IEEE Industry Applications Society in 1986, the William E. Newell Award of the IEEE

Power Electronics Society in 1990, and the Nicola Tesla IEEE Field Award from the IEEE Power Engineering Society in 1995. 